\title{
A pesquisa em psicologia clínica: do indivíduo ao grupo
}

\section{Research in clinical psychology: from the individual to the group}

\author{
Maria da Penha NERY ${ }^{1}$ \\ Liana Fortunato COSTA ${ }^{2}$
}

\begin{abstract}
Resumo
O artigo traça uma breve trajetória da pesquisa em Psicologia Clínica e atenta para a direção que vêm tomando as investigações que adotam como objeto de estudo a relação grupal. Observa-se grande complexidade nos contextos terapêuticos disponíveis atualmente, os quais acolhem demandas advindas de grupos cada vez maiores, de espaços mais difusos e ambientes menos específicos. Esta trajetória se caracterizou por um movimento de flexibilização do contexto clínico, no sentido de admitir que a construção de significados e sentidos, surgidos da relação terapêutica grupal, se constituiu em um foco válido de discussão. Finalmente, aponta-se a sociatria moreniana como uma proposta de liberação da espontaneidade/criatividade, que favorece a resolução de conflitos relacionais e sociais.
\end{abstract}

Unitermos: Psicodrama. Psicologia clínica. Psicoterapia de grupo.

\begin{abstract}
This article aims to outline a brief history of the research into Clinical Psychology, paying particular attention to the direction that this research is taking by way of a study centered around group relationships. We recognize the complexity in the therapeutic contexts that are presently available and which receive demands arising from increasingly larger groups, more expansive spaces and less specific environments. We can see that this history was characterized by a movement of flexibility in the clinical context towards accepting that the construction of meanings and senses that arise from the group therapy relationship, constitutes a valid source for discussion. Finally we would indicate the Sociatry of Jacob Levy Moreno as a proposal for the liberation of spontaneity-creativity which benefits the resolution of relational and social conflicts.
\end{abstract}

Uniterms: Psychodrama. Clinical psychology. Group psychotherapy.

A Psicologia Clínica vem ampliando seu escopo de investigação para além do aspecto individual, pois já não entende o ser humano sem considerá-lo como parte dos contextos em que está inserido. Necessita, cada vez mais, definir como objeto de estudo as relações grupais, e não apenas o indivíduo isoladamente. Dutra (2004) mostra esta mudança de rumo da pesquisa nesta área, apontando a necessidade de se considerar o contexto social na observação clínica. Os elementos presentes na prática clínica, e que a caracterizam, incluem: a observação acurada do ser, a escuta, o sofrimento psíquico e a expressão da subjetividade. Estes elementos, cada vez mais, passam a ser considerados também em relação ao contexto, o que leva à

$\boldsymbol{\nabla} \mathbf{\nabla} \boldsymbol{\nabla}$

1 Associação Brasiliense de Psicodrama, Curso de Formação em Psicodrama. Brasília, DF, Brasil.

2 Universidade de Brasília, Instituto de Psicologia. ICC Sul, Campus Darcy Ribeiro, 70910-900, Brasilia, DF, Brasil. Correspondência para/Correspondence to: L.F. COSTA. E-mail: <lianaf@yahoo.com.br>. 
observação das relações, das escolhas e dos movimentos grupais. A pesquisa em Psicologia Clínica pode privilegiar esses aspectos e, deste modo, realizar estudos de grupos, com enfoque clínico, voltados para o conhecimento da dinâmica grupal e da ética presente nas práticas que se centram nas relações.

Batista Pinto (2004) aponta que a Psicanálise, como método de intervenção e de pesquisa, também tem contribuído especificamente para o avanço da pesquisa qualitativa clínica no Brasil. Os métodos clínicos da Psicanálise, segundo esta autora, mostram-se propícios para a construção de um "modelo específico de pesquisa" (p.77). Da mesma forma, o Psicodrama consiste em um método de ação terapêutica, também indicado como método de pesquisa.

Em termos históricos, a Psicologia Clínica se desenvolveu com a Psicanálise e com estudos psicológicos interdisciplinares. Os casos clínicos eram abordados sempre do ponto de vista das psicopatologias, dentro de uma concepção na qual o sofrimento era sempre visto como conseqüência de influências vindas do interior do indivíduo, de sua própria mente.

Na história da medicina, o médico, usando métodos positivistas, devia conhecer e descrever o fato clínico, que se resumia ao adoecer físico do indivíduo, com o objetivo de tratá-lo. Porém, no final do século XIX, observou-se a importância da subjetividade para a prática médica, pois algumas enfermidades, entre elas, os quadros neuróticos, não podiam ser explicadas pela anatomia, fisiopatologia ou pela bacteriologia clássicas (Entralgo, 1969). Freud contribuiu para esta "revolução do sujeito", questionando o diagnóstico tradicional, que se baseava apenas no exame objetivo do corpo e estava focado no olhar do médico. Ele propôs uma nova forma de análise clínica, na qual "a escuta das queixas, experiências do doente e a análise do inconsciente, cujos conteúdos também fundamentam o adoecimento físico" (Knobel, 2004, p.83), também fossem levadas em conta.

No atual momento sócio-cultural, início do século XXI, os estudos e as práticas clínicas derivadas da subjetividade e do sujeito que adoece começam a enfrentar novos limites. A realidade socioeconômica mundial, a globalização e o avanço tecnológico renovaram as questões da psicologia clínica, entre elas: o

242 que é normal e o que é patológico, como as articulações entre o indivíduo e a sociedade interferem na prática psicoterápica, como a cultura e psicopatologia se conjugam na área clínica, qual a atual especificidade da relação paciente/psicoterapeuta e qual o papel do psicólogo na sociedade.

A Psicologia Clínica necessitou expandir a concepção do fato clínico, quando admitiu que, em determinados fatos sociais (entre eles, a desigualdade social, a liberdade sexual, a intolerância com as diferenças, o racismo, a corrupção, o tráfico de drogas, o trabalho escravo, o desemprego, a fome, a miséria, a violência, o terrorismo e as guerras para a manutenção do capitalismo desumano), e em fatos naturais (como as catástrofes ecológicas), estão presentes sofrimentos humanos e grupais, que exigem intervenções terapêuticas cada vez mais inovadoras.

Batista Pinto (2004) aponta que a pesquisa em Psicologia Clínica pode se beneficiar do princípio que rege o progresso da ciência: a influência do conhecimento novo, que traz contradições e evidências de paradoxos nos fenômenos observados, possibilitando que o estudioso de um determinado tema compreenda as dimensões que se complementam ou se suplementam de um objeto estudado. Segundo esta autora, teoria e método são a base da pesquisa científica, e permitem que se possa conhecer o conjunto de problemas relativos ao foco de estudo. Esta definição ampara a escolha do método qualitativo para se aprofundar o conhecimento sobre as várias nuances de informações que o grupo, em contexto clínico ou de intervenção psicossocial, possa oferecer.

Dutra (2004) acrescenta que uma observação acurada das práticas clínicas e das pesquisas e/ou intervenções permite que se questione outras práticas e demandas ainda não observadas e/ou descritas. A intervenção clínica não necessariamente exige que se considere o contexto, mas que se teça reflexão sobre este. A realidade atual se apresenta flexível, quando se considera, como condição de ajuda a determinadas populações, contextos não-clínicos, mas que possuem possibilidades terapêuticas (Cruz, 2004). Esta preocupação com a criação de contextos não-clínicos, mas terapêuticos, pode se estender para uma reflexão sobre a pesquisa clínica e a criação de metodologias que forneçam acesso, por exemplo, à expressão grupal, e que também funcionem como intervenções potentes. 
Então, diante dessas perspectivas científicas, alude-se ao pensamento de Moreno (1975), que propôs, logo no início do século XX, o conhecimento e o tratamento do indivíduo inserido na sociedade. Seus estudos possibilitaram a criação da Psicoterapia de Grupo e os métodos ativos de intervenção sociátrica. Este autor propôs um veículo terapêutico especial, o "espaço para a ação", para que os participantes dos grupos vivenciem seus papéis sociais e latentes, desvelando suas tramas ocultas. A experiência suplementar da situação conflituosa contribui para a resolução dos dramas relacionados ao fato clínico. Surge, então, "o diagnóstico ex actio - a ação do paciente no palco, que traz subjetivamente a reprodução objetivada da doença" (Knobel, 2004, p.83). Pode-se dizer que Moreno conquistou a "revolução do sujeito criativo", que, de diversas maneiras, está nas situações, adapta-se e vive no mundo benfazejo, hostil ou neutro.

\section{Diferentes dimensões da intervenção em Psicologia Clínica}

O percurso da intervenção e da pesquisa em Psicologia Clínica, desde o tratamento individual até o tratamento dos grupos in situ, é amplo. Porém, pode-se traçar uma síntese desde as características da clínica individual até a clínica sócio-comunitária, buscando contribuir para a compreensão do desenvolvimento das práticas psicoterápicas e sociátricas, com base na seguinte afirmação de Moreno (1983, p.54): "Pode-se cartografar uma parte considerável do movimento psicoterapêutico desde o começo do século, tomando o paciente no divã e tirando-o daí para a cadeira, daí para seus próprios pés e, por fim, permitindo-Ihe atuar ao vivo seus relacionamentos".

A Tabela 1 ilustra a complexidade dos contextos terapêuticos que estão disponíveis a quem procura ajuda para a resolução de conflitos e sofrimentos. Percebe-se que, gradativamente, a clínica estende suas ofertas a grupos cada vez maiores, a espaços mais difusos e ambientes menos específicos, como é o caso da Terapia Comunitária e/ou dos Grupos Multifamiliares e/ou Psicodramas públicos. Por outro lado, esta abrangência conserva ainda uma escuta dialógica e hermenêutica, com a utilização de técnicas ativas e uma interpretação das situações-problema do ponto de vista individual, grupal e sócio-comunitário. A resolução de conflitos passa do âmbito pessoal para a criação conjunta de soluções.

A Tabela 2 demonstra, em síntese, as principais técnicas usadas nos diferentes métodos terapêuticos. $\mathrm{Na}$ abordagem grupal, considera-se tanto a fala individual quanto a do grupo como um todo. Muitas são as técnicas de ação: dramatizações, role-playing, jogos dramáticos, dinâmicas grupais. Os terapeutas são observadores-participantes, e mantêm um contato com os sujeitos profundamente marcado por uma ética, pautados em um compromisso que se estende além das questões terapêuticas. Os processos resolutivos dos conflitos também têm uma dimensão sócio-educativa. Surgem intervenções com ausência de setting específico, que ocorrem nos departamentos das empresas, nas residências das famílias, nas ruas, escolas, hospitais, sindicatos, associações, no contexto judicial e nos espaços sociais (Costa, Sudbrack, Guimarães, Pessina \& Santana, 2006; Dias, Lima \& Marra, 2006; Fleury \& Marra, 2005abc; Nery \& Conceição, 2006). Isto porque também se busca a responsabilidade pessoal em relação aos conflitos sociais, e esta traz encaminhamentos sóciopolíticos. Os contextos com possibilidades terapêuticas revelam a complexidade dos fenômenos sociais, e as observações sobre esta complexidade exigem conquista de outros modos e espaços terapêuticos ainda não revelados.

\section{A pesquisa em Psicologia Clínica}

Sobre o percurso da pesquisa em Psicologia Clínica, talvez esta tenha se iniciado com Foucault (1980), ao traçar os limites do que chamou de nascimento da clínica. Segundo o autor, o ato clínico estava inicialmente afeito ao médico, o qual deveria ter uma tarefa que é da ordem política, porque suas denúncias e diagnósticos deveriam incluir uma crítica aos maus governos e aos desmandos sociais. Hoje, entende-se que o ato clínico na Psicologia Clínica se caracteriza por uma observação acurada, uma proposta de vinculação, e um contrato de sigilo que envolve ambas as partes: o clínico e aquele que vai se beneficiar da clínica realizada (Cirillo, 2000).

Dutra (2004) aponta as características da prática clínica: uma escuta clínica, um sofrimento psíquico e a subjetividade. Pode-se estender esta afirmação para o 
contexto da pesquisa em Psicologia Clínica. Na medida em que se enfatiza uma clínica grupal, ressalta-se também o caráter político presente nesta prática. As preocupações éticas se voltam para a importância do compromisso do pesquisador com as influências e conseqüências da ação da pesquisa sobre o grupo pesquisado.

González Rey (1993) critica a postura tradicional da investigação da personalidade, que sempre precisou utilizar um marco descritivo, e que tendia a considerar os traços como nocivos e indutores de patologias, sem que fosse considerado o sujeito em seu ambiente concreto e relacional. Estes traços são vistos como bons ou maus, e em dimensão abstrata. No entanto, para este autor, a doença é um processo vivo e que está ligado a aspectos vulneráveis do indivíduo, que identificam um processo em curso. Para a pesquisa nesta área de saúde, o sujeito é visto como um objeto, com uma atividade que é intencional e que está em permanente mudança, por sua interação com os múltiplos aspectos de sua vida social. Os estudos da subjetividade de González Rey (2005a) são bastante aproximados da Psicologia Clínica. Ao propor o estudo da subjetividade como uma categoria central e suas configurações subjetivas, González Rey inclui o valor da produção dos sentidos singulares das ações e discursos de cada sujeito. Este é o campo de interpretação da Psicologia Clínica.

Da mesma forma, Turato (2003) toma como ponto de partida do método de pesquisa clínico-qualitativo a interpretação clínica dos sentidos e das significações dadas aos fenômenos, pela observação e investigação do sujeito em seu campo natural de pertencimento e atuação.

O ato de investigar requer uma série de outras habilidades que vão dar conta de todos os passos da pesquisa, desde observar, planejar, proceder, até escrever e publicar seus achados, mesmo que sejam em uma área tão hermética como a clínica. Mezan (1998) dá uma excelente contribuição ao ato investigativo, quando se propõe a discorrer sobre a escrita da clínica, chamando atenção para aspectos tais como a teorização, a interpretação, aqueles que dizem respeito a quem escreve (ou quem pesquisa), a argumentação, a discussão e a

244 defesa da "tese" presente no caso clínico.
A trajetória de desenvolvimento da pesquisa aqui referida caminhou distanciada da Psicologia Clínica. Mas, hoje, parece que não há mais um assombro em se fazer clínica e pesquisa simultaneamente. Já houve época em que estas duas dimensões, intervenção e conhecimento, mostraram-se bastante díspares. Guirado (1997) entende que a clínica está voltada para a singularidade do sujeito, enquanto a ciência está voltada para a universalidade do saber. Durante bom tempo, parece que estas duas dimensões foram antagônicas, como se o caminho do particular para o geral e do geral para o particular não proporcionasse conhecimento em abrangência sobre o todo e suas partes. Moreno (1975), Santos (1998), Demo (2001) apontam que o psicólogo clínico é um observador e pesquisador natural. Pesquisar e conhecer o sujeito é conhecer uma organização particular e sua história de relações e de vínculos (Guirado, 1997). A Psicologia Clínica elegeu o discurso e sua análise como objeto de estudo, como uma especificidade no seu modo de atuar.

Esta trajetória se caracterizou por um movimento de flexibilização do contexto clínico, no sentido de admitir que o produto da relação entre o sujeito e o terapeuta, ou seja, a construção de significados e sentidos surgidos desta relação, tornou-se um foco válido de discussão e exemplaridade (Demo, 1998).

Retomando as Tabelas 1 e 2, cabe a pergunta: e as influências destas mudanças sobre a pesquisa clínica? Com relação ao discurso do sujeito da pesquisa, na medida em que as intervenções sejam mais abrangentes e na consideração de outras falas, tem-se as conversações (Anderson \& Goolishian, 1993). Estas passam a ser o foco do interesse do pesquisador, que considera não só os aspectos individuais presentes no diálogo, mas também os aspectos interacionais, tendo que adotar métodos de coleta de informações que dêem conta de conhecer a fala grupal, as interações e a forma como o grupo desenvolve o tema de pesquisa. Esta mudança exige um pesquisador mais ativo, com uma experiência clínica de abordagem tanto individual como grupal e o uso de instrumentos de coleta de informações cabíveis para a captação das conversações, como, por exemplo, o grupo focal (Berg, 1998).

Os ambientes pesquisados se agigantam, ou seja, se tornam cada vez mais públicos, institucionais e relativos a circunstâncias com saberes interdisciplinares. 
Isto se reflete na construção de objetos de pesquisa que abrangem situações que são de âmbito mais geral, de interesse grupal e/ou social, ou que contêm a dimensão clínica da pesquisa, associada a outros tipos de ações/intervenções, como a intervenção judicial (Costa, Penso \& Almeida, 2005). Torna-se necessária ao pesquisador a habilidade de contato, uma vez que uma série deles será realizada fora do âmbito clínico da pesquisa (Costa, Penso \& Almeida, 2006).

A relação do pesquisador com os pesquisados também tem se transformado. Se, na maioria das vezes, a pesquisa clínica oferece uma situação de contato com uma, duas pessoas ou, talvez, uma família, quando se trata de pesquisa com grandes grupos, a relação se dá

Tabela 1. Relação entre os tipos de intervenção individual e grupal quanto ao contexto, relação terapêutica e enfoque clínico.

\begin{tabular}{|c|c|c|c|}
\hline Тipo & Setting e instrumental & Relação terapêutica e estética & Enfoque clínico e tipo de contato \\
\hline $\begin{array}{l}\text { Psicanálise/psicoterapia } \\
\text { psicodinâmica }\end{array}$ & Consultório & Bipessoal; monólogo & Conflitos psíquicos; transferência \\
\hline $\begin{array}{l}\text { Terapia centrada na pessoa, } \\
\text { Gestalt terapia }\end{array}$ & Consultório & Bipessoal; diálogo & Centrado na pessoa \\
\hline Psicodrama bipessoal & Consultório; tablado & Relação humana; ação dramática & Criação conjunta de resoluções \\
\hline Psicodrama em grupo & Consultório; tablado & $\begin{array}{l}\text { Fenômenos grupais e ação } \\
\text { dramática }\end{array}$ & Criação conjunta de resoluções \\
\hline Terapia conjugal e familiar & Consultório; espaço grupal & Interação familiar; fala; ação & $\begin{array}{l}\text { Vínculos familiares; criação con- } \\
\text { junta de resoluções }\end{array}$ \\
\hline Terapia comunitária & $\begin{array}{l}\text { Comunidade/instituição; } \\
\text { espaço grupal }\end{array}$ & $\begin{array}{l}\text { Relações pessoais, grupais e } \\
\text { comunitárias; fala; ação }\end{array}$ & $\begin{array}{l}\text { Demandas pessoais e grupais; } \\
\text { socioterapia }\end{array}$ \\
\hline Intervenção psicossocial & $\begin{array}{l}\text { Instituições de serviço social/ } \\
\text { justiça; espaço grupal }\end{array}$ & $\begin{array}{l}\text { Relações pessoais, grupais e comu- } \\
\text { nitárias; fala; ação }\end{array}$ & $\begin{array}{l}\text { Resolução pontual de conflitos e } \\
\text { encaminhamento }\end{array}$ \\
\hline Socioterapia/sociodrama & $\begin{array}{l}\text { Comunidade; instituições; } \\
\text { espaço grupal }\end{array}$ & $\begin{array}{l}\text { Relações grupais e intergrupais; } \\
\text { fala; ação }\end{array}$ & $\begin{array}{l}\text { Conflitos intergrupais; criação con- } \\
\text { junta de soluções }\end{array}$ \\
\hline Grupos multifamiliares & Comunidades; espaço grupal & $\begin{array}{l}\text { Relações familiares e comunitárias; } \\
\text { fala; ação. }\end{array}$ & Criação conjunta de resoluções \\
\hline
\end{tabular}

Tabela 2. Relação entre os tipos de intervenção individual e grupal quanto ao método, objetivos e conceitos.

\begin{tabular}{|c|c|c|c|c|}
\hline Tipo & Métodos e técnicas & Objetivos & Conceitos fundamentais & Referências \\
\hline $\begin{array}{l}\text { Psicanálise/psicoterapia } \\
\text { psicodinâmica }\end{array}$ & $\begin{array}{l}\text { Associação livre, interpre- } \\
\text { tação dos significados }\end{array}$ & $\begin{array}{l}\text { Catarse de ab-reação, } \\
\text { auto-responsabilização }\end{array}$ & $\begin{array}{l}\text { Inconsciente, complexo } \\
\text { de Édipo }\end{array}$ & $\begin{array}{l}\text { Brenner, 1975; } \\
\text { Dewald, } 1973\end{array}$ \\
\hline $\begin{array}{l}\text { Terapia centrada na } \\
\text { pessoa, Gestalt terapia }\end{array}$ & $\begin{array}{l}\text { Interação centrada na } \\
\text { pessoa }\end{array}$ & Auto-responsabilização & Aqui e agora & $\begin{array}{l}\text { Rogers, 1985; } \\
\text { Pearls, } 1977\end{array}$ \\
\hline Psicodrama bipessoal & Ação terapêutica & Catarse de integração & Co-inconsciente & Moreno, 1975 \\
\hline Psicodrama em grupo & $\begin{array}{l}\text { Ação do indivíduo no } \\
\text { grupo }\end{array}$ & Catarse de integração & Sóciodinâmica & Moreno, 1974 \\
\hline Terapia conjugal e familiar & Questionamento circular & $\begin{array}{l}\text { Conscientização da } \\
\text { interação }\end{array}$ & Leitura sistêmica & Boscolo et al., 1993 \\
\hline Terapia comunitária & Participação ativa & $\begin{array}{l}\text { Conscientização em } \\
\text { conflitos grupais }\end{array}$ & Identificações & Barreto, 1990 \\
\hline Intervenção psicossocial & Mediação & Mediação de conflitos & Compromisso mútuo & Cirillo, 2000 \\
\hline Socioterapia/sociodrama & Ação intergrupal & Catarse de integração & Sociometria & Moreno, 1974 \\
\hline Grupos multifamiliares & Estratégias de ação & $\begin{array}{l}\text { Mediação da interação } \\
\text { familiar }\end{array}$ & Identificações & $\begin{array}{l}\text { Costa, 1999; Holzmann \& } \\
\text { Grassano, } 2002\end{array}$ \\
\hline
\end{tabular}


com muitos sujeitos ao mesmo tempo (Zampieri, 1996). Neste caso, o pesquisador assume vários papéis de forma simultânea, necessitando, inclusive, de auxiliares que dividem, com ele, a responsabilidade de co-autoria da pesquisa. A pesquisa desenvolvida por esta autora é um exemplo desta situação, pois ela foi diretora de um Sociodrama, terapeuta, coordenadora de toda a ação e negociadora com a instituição municipal que foi parceira na pesquisa-ação.

Outro aspecto importante diz respeito a métodos de pesquisa de natureza interventiva, entre eles, a pesquisa-ação (Barbier, 2002) ou a pesquisa interventiva (Levy, 2001), que caracterizam, cada vez mais, as opções de pesquisa dos pesquisadores clínicos. As que contêm uma dimensão de ação revelam-se pertinentes para os contextos grupais, e os seus objetos se configuram tanto para as relações do indivíduo com o mundo ao seu redor, como para as relações entre os indivíduos, enfocando a subjetividade individual e a social (González Rey, 2005b). Segundo González Rey (1999), novos métodos de interpretação dos sentidos construídos nestas relações se fazem necessários.

\section{A socioterapia}

Depois de relatado o percurso do desenvolvimento das psicoterapias e pesquisas clínicas individuais, relacionais e grupais, é interessante abordar como a Socionomia (Moreno, 1972) e seus métodos sociátricos podem contribuir para a evolução desse processo. Os métodos sociopsicodramáticos e sociométricos de tratamento grupal explicitam a dinâmica social por meio do protagonista (ou de temas protagônicos). O protagonista é o participante que favorece a expressão de conflitos de todos os membros do grupo. A pesquisa interventiva grupal concebe o sofrimento psíquico expresso por um indivíduo como um sofrimento interpsíquico, pois abrange o campo social e por este é envolto.

O compartilhar do que se pensa, do que se sente e das emoções expressas é vivido não apenas na linguagem verbal, mas também nas atitudes, na espacialidade e corporalidade, nos atos, nos processos pré-semânticos e não-verbais dos participantes. Estas trocas exigirão que o terapeuta saia da "ânsia simbólica", ou seja, da crença de que apenas o símbolo - ou a sim- bolização - promoverá a cura. O pesquisador-terapeuta precisará enfrentar outros níveis de acolhimento, de compreensão e de elaboração do sofrimento de cada um e do grupo, inclusive dele próprio com o grupo. 0 sistema terapêutico é co-criado por todos. As regras dos grupos estão ligadas às suas construções da realidade e, portanto, são modificáveis, mediante intervenções destinadas a reconstruir essas realidades (Seixas, 1992).

O fato clínico é revelado por um confronto sociométrico, pois há momentos em que a co-criação produz alguma disfunção, que prejudica o equilíbrio social (Nery, 2003). Em um grupo, o sofrimento está presente nestas situações conflituosas, angustiantes, alienantes, paralisantes ou violentas. E o fato clínico se manifesta em diversos sinais, por exemplo, o conteúdo e a forma das verbalizações; a expressão e movimentos corporais; o clima emocional do grupo, a localização espacial dos participantes; os processos de escolhas entre os indivíduos etc. O pesquisador-terapeuta tem a tarefa de detectar os sinais dos sofrimentos do grupo e dos participantes, a partir dos quais se revela o fato clínico e, sobre ele, iniciar a intervenção terapêutica. 0 conhecimento informado é da situação, e é esta que o ser humano vive, com uma concretude demarcada pelo momento vivido (aqui/agora - tempo psicológico concreto e histórico, que carrega em si o passado e o futuro), pelo contexto histórico-cultural, pelos papéis e vínculos sociais que a compõem.

\section{Pesquisa interventiva de grupos}

A situação de pesquisa interventiva grupal permite a vivência da epopéia e do gênero do teatro em sua ampla dimensão. Isso porque o ser humano é muito complexo para ser compreendido pela fala, na estética do monólogo; muito dinâmico para ser captado quando se centra em sua realidade, na estética do diálogo; e muito surpreendente quando se volta para suas relações, na estética do drama. Todas as estéticas de pesquisa e terapêutica têm, portanto, alcances e limites.

O pesquisador, na pesquisa interventiva, precisa conquistar um posicionamento global em relação ao outro que pressupõe a superação (com a absorção) da escuta especializada do psicólogo/pesquisador (de- 
fendida pela Psicanálise) e da centralização no cliente (defendida pela Abordagem Centrada na Pessoa), propondo a inversão de papéis (defendida pelo Psicodrama). A inversão de papéis é a postura que faz a pessoa se imaginar na alma do outro, se colocar em sua totalidade, na sua singularidade de sujeito (submetido a processos históricos, sociais e culturais) e de protagonista da história (dotado do fator espontaneidade-criatividade) (Moreno, 1975). Este posicionamento global torna o pesquisador um terapeuta-interventor-observador-participante. A pesquisa interventiva de grupos contém, pois, uma multiplicidade de fatores, que exigem métodos e técnicas mais próximas da realidade.

\section{Métodos qualitativos para a pesquisa sobre grupos}

Atualmente, as pesquisas sociais re-significam a categoria do "ser" e seu atributo "social", na busca da compreensão sobre a relação que vincula os membros de um grupo. A epistemologia das últimas décadas do século XX recoloca os processos de subjetivação na ordem da comunicação intersubjetiva, re-configurando também os métodos de investigação e de intervenção científicas (González Rey, 1999; Moreno, 1974; Santos, 1998). Os pesquisadores tentam encontrar métodos cada vez mais eficientes para captar o "ser social", mantendo-se as especificidades do "sujeito"e do "social", de tal forma que o socius se integre à constituição da subjetividade.

A sociedade sempre recorreu a meios sociais e culturais para a libertação ou para opressão do homem. A ciência, a religião, a arte, o esporte, dentre tantas produções humanas, podem minimizar os sofrimentos da humanidade ou exacerbá-los. Foucault (2002) preconizou as práticas de poder e a construção da verdade, advindas das instituições, para disciplinar, controlar e vigiar o homem, tornando-o e o mantendo dócil diante das opressões e dos saberes demarcadores de padrões que suprimem a diversidade e a criatividade. No entanto, há também o belo, o conhecimento e os métodos criados por homens que resistem politicamente e que reativam valores universais, como os direitos humanos e a bioética. A produção científico-cultural que interrompe a destruição e a opressão busca um efeito catártico.
Os rituais religiosos e culturais, por exemplo, auxiliam o ser humano a enfrentar situações de insegurança e o ajudam a manter o status quo socioeconômico da comunidade. Segundo Reñones (1996), no contexto do ritual, "uma nova forma de estar no mundo toma lugar de uma antiga, muito mais para ampliar o horizonte, do que para castrá-lo" (p.40). O ritual mobiliza, portanto, um processo liberador, associado à catarse.

O termo Kátharsis apareceu no século VIII a.C, na Odisséia de Homero, e significava o processo de transformação que o iniciado em alguma religião passava, para poder compreender as profecias. Hipócrates adaptou ao termo o sentido de limpeza, Platão adicionou-lhe a questão moral de alívio da alma e Aristóteles afirmou que a tragédia grega trouxe uma função catártica para a humanidade, pela via psíquica do processo de identificação da platéia com o protagonista. A cultura latina revestiu o termo catarse de significado médico e, no contexto religioso das instituições cristãs, ele se vincula às noções de arrependimento dos pecados (Reñones, 1996).

A Psicanálise, em particular, por meio das descobertas de Freud e Breuer (Freud, 1949/1967), desenvolve o estudo dos mecanismos intrapsíquicos e o tratamento das psicopatologias. Os métodos hipnóticos e, posteriormente, o método da associação livre, dão origem ao conceito de catarse de ab-reação. Esta é a expressão da (re)vivência da tragédia pessoal do analisando, por meio de suas lembranças e de sua fala.

Para além da Psicanálise e incorporando seus conhecimentos, a literatura das Ciências Sociais oferece subsídios teóricos para a construção e o aperfeiçoamento de técnicas e métodos socioterápicos, que promovam novos tipos de catarse e de mudanças pessoais e sociais. Neste sentido, é possível questionar: quais técnicas e procedimentos podem ser usados pelos cientistas sociais que contribuam para a construção de uma cidadania digna e emancipada, no mundo atual?

No Brasil, por exemplo, Freire (1976) desenvolveu metodologias educacionais, na forma de debates sócio- políticos, libertadoras do sujeito alienado. A consciência política dos cidadãos foi ampliada, contribuindo para a organização dos movimentos sociais, que conquistaram leis propiciadoras de mais justiça social, a partir da Constituição de 1988. 
Voltando à noção de catarse proveniente do teatro, ressalta-se a valiosa contribuição de Boal (1977) com o Teatro do Oprimido, que é extremamente válida para o Brasil. Desenvolvido em plena época de ditadura militar, esse teatro contribuiu para a expressão e liberação do sofrimento popular.

Outro método ativo é o Teatro Espontâneo, criado por Moreno (1975), em 1921. OTeatro Espontâneo foi um dos fundamentos do Teatro do Oprimido. No teatro espontâneo, o sujeito representa os dramas da sua sociedade dentro de personagens que desenvolvem seus scripts no momento da representação. Neste teatro, o sujeito vive uma catarse dramática, que libera sua espontaneidade-criatividade, favorecendo-lhe a resolução de conflitos relacionais e sociais.

O Teatro Espontâneo deu origem aos métodos sociátricos, entre eles, a Psicoterapia de Grupo, os Jogos Dramáticos, o Role Playing, o Psicodrama e o Sociodrama. Uma das funções fundamentais dos métodos sociátricos é a de dar voz aos atores sociais, principalmente às minorias, entre elas, crianças, prostitutas, negros, prisioneiros, os quais, em uma dramaturgia espontânea, protagonizam seus dramas, buscam saídas para seus conflitos e desenvolvem a cidadania. No Psicodrama, por exemplo, o sujeito se torna autor de seu próprio drama, ou do grupo que representa seu drama, por meio de um protagonista ou dele próprio.

A ação cênica dos métodos ativos percorre estados emocionais compartilhados, com certa preocupação estética, pois busca reproduzi-los (mimesis), modificá-los pela ação (poesis) e produzir alívio (catharsis). O indivíduo refaz-se e se revê no processo relacional. Não há desempenho de papel social sem o papel complementar. Então, a catarse de integração pressupõe o ser-humano-em-relação, ou seja, pressupõe vínculo, grupo, intersubjetividade e vivência.

Segundo Moreno (1975, p.65), a catarse resultante dos métodos sociátricos é a catarse de integração. 0 autor nos diz:

A teoria psicodramática desenvolveu a idéia de catarse em quatro direções: a somática, a mental, a individual e a grupal. ... na situação psicodramática, o paciente recebe as três formas básicas de catarse mental, uma no autor - criador e paciente do drama privado - a outra no ator que lhe dá vida e a terceira no público que co-sente os acontecimentos... . Pela integração sintética de todos os elementos, pode ser obtida a catarse total.
A catarse de integração vivifica a subjetividade por meio da espontaneidade (fator "e"). Espontaneidade é a capacidade de dar respostas novas a problemas antigos, ou respostas adequadas a problemas novos. A espontaneidade é o pólo oposto da conserva cultural. A conserva cultural é o produto de uma sociedade, caracterizado pela arte, mitos, costumes etc. Ambas estão em um continuum. Em termos individuais, a conserva está presente nas expressões e condutas conservadas, que se mantém ao longo da história do indivíduo. A catarse de integração, portanto, libera o homem rotulado, robotizado, padronizado, submetido às intempéries dos donos do poder e de seus próprios boicotes inconscientes.

Moreno (1974) usou o termo sociatria para se referir ao conjunto de métodos sociátricos. Para o autor, sociatria é o tratamento dos grupos doentes. Nessa definição, ele ainda era influenciado por uma visão sócio-psicopatológica, de acordo com o modelo médico-biológico antigo. Porém, atualmente, redefine-se esse enfoque de acordo com a epistemologia socionômica: sociatria é um conjunto de métodos terapêuticos para tratamento de grupos em sofrimento ou em conflito desagregador.

Em seus projetos, Moreno buscava uma nova ordem mundial terapêutica ou a superação das ideologias comunistas e capitalistas, perseguindo a convivência humana dentro de valores cosmodinâmicos, que gerassem o bem-estar tanto individual como coletivo. As propostas de Moreno, apesar de terem algumas reminiscências de modelos arcaicos, adiantaram concepções hoje apregoadas pelo paradigma científico moderno.

\section{Considerações Finais}

Historicamente, percebe-se que o psicólogo clínico superou estigmas e barreiras de um trabalho centrado no indivíduo e na expressão de sua subjetividade, para o conhecimento da interconexão indivíduo/sociedade. A trajetória evidenciou que a Psicologia Clínica se voltou da influência da cultura na personalidade para as inserções sócio-históricas sobre a ação dos indivíduos, e tem se dirigido para as ruas, praças e instituições de cuidado de crianças, de detentos, de 
pessoas institucionalizadas, desenvolvendo métodos que tratam os indivíduos em seus contextos sócio-culturais.

As mudanças ocorridas nos contextos de pesquisa em Psicologia Clínica revelam possibilidades de oferecimento de métodos que atendam a demandas específicas de situações-problema. Há métodos que respondem ao sofrimento de pessoas que, dependendo da indicação terapêutica, têm melhor rendimento e eficácia nas intervenções grupais. As realidades socioeconômicas, educacionais, de gênero ou raciais têm que ser pensadas de formas diferenciadas, pois contêm sofrimentos diferenciados. Para tal, faz-se necessário que sejam descritas experiências de pesquisa que envolvam as situações grupais e que se dirijam a grupos minoritários que têm permanecido fora do alcance da curiosidade científica, por não se coadunarem com os métodos disponíveis para a pesquisa clínica. Chama-se a atenção do leitor para as possibilidades oferecidas pelo referencial teórico e metodológico do Psicodrama, diante desse novo momento da Psicologia Clínica.

\section{Referências}

Anderson, H., \& Goolishian, H. (1993). O cliente é o especialista. Uma abordagem para terapia a partir de uma posição de "Não Saber". Nova Perspectiva Sistêmica, $2(3), 8-23$

Barreto, A. (1990). Terapia, cultura e comunidade. Trabalho apresentado no II Congresso Brasileiro de Terapeutas de Família. Belo Horizonte.

Batista Pinto, E. (2004). A pesquisa qualitativa em psicologia clínica e a pesquisa em psicanálise. Psicologia USP, 15 (1/2), 71-80

Barbier, R. (2002). A pesquisa-ação. Brasília: Plano.

Berg, B. L. (1998). Qualitative research methods for the social sciences. Boston: Allyn \& Bacon.

Boal, A. (1977). Teatro do oprimido e outras poéticas políticas. Rio de Janeiro: Civilização Brasileira.

Boscolo, L., Cecchin, G., Hoffman, L., \& Penn, P. (1993). A terapiafamiliar sistêmica de Milão. Conversações sobreteoria e prática. Porto Alegre: Artes Médicas.

Brenner, C. (1975). Noções básicas de psicanálise. Introdução à psicologia psicanalítica. Rio de Janeiro: Imago.

Cirillo, S. (2000). El cambio en los contextos no terapeuticos. Buenos Aires: Paidós.

Costa, L. F. (1999). Reuniões multifamiliares: uma proposta de intervenção em Psicologia Clínica na comunidade. In
M. G. T. Paz \& A. Tamayo (Orgs.), Escola, saúde e trabalho: estudos psicológicos (pp.155-180). Brasília: EdUnB.

Costa, L. F., Penso, M. A., \& Almeida, T. M. C. (2005). O grupo multifamiliar como um método de intervenção em situações de abuso sexual infantil. Psicologia USP, 16 (4), 121-146.

Costa, L. F., Penso, M. A., \& Almeida, T. M. C. (2006). Nos bastidores da pesquisa: dificuldades no procedimento metodológico em situações-limite. Psico PUCRS, 37 (2), 175-181.

Costa, L. F., Sudbrack, M. F. O., Guimarães, F. L., Pessina, L. M., \&Santana, P. (2006). Recursos psicodramáticos no contexto judicial. In H. J. Fleury \& M. M. Marra. Práticas grupais contemporâneas. A brasilidade do psicodrama e de outras abordagens (pp.69-83). São Paulo: Ágora.

Cruz, H. M. (2004). Terapia sistémica: um nuevo movimiento social? Sistemas Familiares y otros sistemas, 20 (3), 7-17.

Demo, P. (1998). Pesquisa qualitativa. Busca de equilíbrio entre forma e conteúdo. Revista Latino Americana de Enfermagem, 6 (2), 89-104.

Demo, P. (2001). Pesquisa einformação qualitativa. Campinas: Papirus.

Dewald, P. (1973). Psicoterapia: un enfoque dinámico. Barcelona: Toray.

Dias, H. G., Lima, J. M., \& Marra, M. M. (2006). Círculo criativo entre diferentes profissionais e abordagem no contexto psicossocial jurídico. In H. J. Fleury \& M. M. Marra (Orgs.), Práticas grupais contemporâneas. A brasilidade do psicodrama ede outras abordagens (pp.85-106). São Paulo: Ágora.

Dutra, E. (2004). Considerações sobre as significações da psicologia clínica na contemporaneidade. Estudos de Psicologia (Natal), 9 (2), 381-387.

Entralgo, P. L. (1969). Elmedicoyelenfermo. Madri:Gadarrama.

Fleury, H. J., \& Marra, M. M. (Orgs.) (2005a). Intervenções grupais nas organizações. São Paulo: Ágora.

Fleury, H. J., \& Marra, M. M. (Orgs.) (2005b). Intervenções grupais na saúde. São Paulo: Ágora.

Fleury, H.J., \& Marra, M. M. (Orgs.) (2005c). Intervenções grupais nos direitos humanos. São Paulo: Ágora.

Foucault, M. (1980). O nascimento da clínica. Rio de Janeiro: Forense-Universitária.

Foucault, M. (2002). Microfísica do poder (17a. ed.). Rio de Janeiro: Graal.

Freire, P. (1976). Ação cultural para a liberdade e outros escritos. Rio de Janeiro: Paz e Terra.

Freud, S. (1967). Esquema del psicoanalisis. In S. Freud, Obras Completas. Madri: Biblioteca Nueva. (Originalmente publicado em 1949).

González Rey, F. (1993). Personalidad, salud y modo de vida. Ciudad de México: Universidad Autônoma de México.

González Rey, F. (1999). La Investigación cualitativa em Psicología: rumbos y desafíos. São Paulo: EDUC. 
González Rey, F. (2005a). O valor heurístico da subjetividade na investigação psicológica. In F. González Rey (Org.), Subjetividade, complexidade e pesquisa em psicologia (pp.27-51). São Paulo: Thomson.

González Rey, F. (2005b). Pesquisa qualitativa e subjetividade. Os processos de construção da informação. São Paulo: Thomson.

Guirado, M. (1997). Vértices da pesquisa em psicologia clínica. Psicol. USP. 8 (1). Retrieved September 14, 2006, from: http://www.scielo.br/scielo.php? script=sci_ arttext\&pid=S0103-65641997000100009\& Ing=en\&nrm=iso doi: 10.1590/S0103-65641997000 100009 .

Holzmann, M. E. F., \& Grassano, S. M. (2002). Multifamílias. Construção de redes de afeto. Curitiba: Integrada.

Knobel, A. M. (2004). Moreno em ato: a construção do psicodrama a partir das práticas. São Paulo: Ágora.

Levy, A. (2001). Ciências clínicas e organizações sociais. Belo Horizonte: Autêntica.

Mezan, R. (1998). Escrever a clínica. São Paulo: Casa do Psicólogo.

Moreno, J. L. (1972). Fundamentos de la sociometria. Buenos Aires: Paidós.

Moreno, J. L. (1974). Psicoterapia de grupo e psicodrama. São Paulo: Mestre Jou.

Moreno, J. L. (1975). Psicodrama. São Paulo: Cultrix.
Moreno, J. L. (1983). Fundamentos do psicodrama. São Paulo: Summus.

Nery, M. P. (2003). Vínculo e afetividade: caminhos das relações humanas. São Paulo: Ágora.

Nery, M. P., \& Conceição, M. I. G. (2006). Sociodrama da inclusão racial: quebrando a inércia. Revista Brasileira de Psicodrama, 14 (1), 105-119.

Pearls, F. S. (1977). Isto é Gestalt (4a. ed.). São Paulo: Summus.

Reñones, A. V. (1996). Cartase de integração: uma pequena viagem etimológica-conceitual. Revista Brasileira de Psicodrama, 4 (2), 35-48.

Rogers, C. (1985). Grupos de encontro. São Paulo: Martins Fontes.

Santos, B. S. (1998). Um discurso sobre as ciências (10a. ed.), Porto: Afrontamento.

Seixas, M. R. D (1992). Sociodrama familiar sistêmico. São Paulo: ALEPH.

Turato, E. R. (2003). Tratado da metodologia da pesquisa clínico-qualitativa. Petrópolis: Vozes.

Zampieri, A. M. F. (1996). Sociodrama construtivista da AIDS. Campinas: Psy.

Recebido em: 30/10/2006

Versão final reapresentada em: 9/4/2007

Aprovado em: 15/8/2007 